\title{
HISTORICAL AND PRESENT-DAY VERTICAL MOVEMENTS ON OLD MINING TERRAINS - CASE STUDY OF THE WALBRZYCH COAL BASIN (SW POLAND)
}

\author{
Jan BLACHOWSKI *, Wojciech MILCZAREK and Piotr GRZEMPOWSKI
}

Wroclaw University of Technology, Faculty of Geoengineering, Mining and Geology, Geodesy and Geoinformatics Unit, Na Grobli 15, 50-421 Wroclaw, Poland

*Corresponding author's e-mail: jan.blachowski@pwr.edu.pl

\begin{tabular}{l} 
ARTICLE INFO \\
\hline Article history: \\
Received 17 February 2015 \\
Accepted 12 May 2015 \\
Available online 2 June 2015
\end{tabular}

Keywords:

Underground coal mining

Abandoned mines

Levelling

Subsidence

Interpolation

GIS

\begin{abstract}
The paper focuses on the analysis of vertical movements on old mining terrains in the final stages of mining and in the period after the end of mining. The study has been done for the Walbrzych Coal Basin area in SW Poland, which has been a hard coal mining centre until the mid-90'ties of the $20^{\text {th }}$ Century. The study has been performed in geographic information systems (GIS) using national precise levelling data from three measurement campaigns in 1972, 1993 and 2014 spanning period of 42 years and using six interpolation functions, i.e.: inverse distance weighted, kriging, local polynomial, natural neighbour, radial basis function and spline. Accuracy of interpolation results has been analysed and maps representing vertical movements on mining terrains in the final two decades of mining and the two decades after the end of mining prepared with the interpolation function with the least error of estimation. The maps have been graphically correlated with plans of the abandoned coal mines and present day development of the surface. Differentiated vertical movements on old mining terrains ranging from - $0.048 \mathrm{~m}$ to $+0,189 \mathrm{~m}$ have been observed in the period after the end of mining (1993-2014) indicating present-day secondary movements on these grounds. The areas of elevation in the second period are associated with the areas of greatest subsidence observed in the first period (1972-1993).
\end{abstract}

\section{INTRODUCTION}

Following the gradual depletion of mineral, nonrenewable, energy resources in traditional mining areas such as for example hard coal, is the growing number of old mining terrains, now revitalised or requiring and undergoing revitalisation, e.g. in the USA, UK, Korea, Japan, Germany, Poland, Czech Republic and many other countries. These old mining terrains usually are located in urban agglomerations associated in the past with coal extraction and now often in need of renewal due to the change of their economic structure. These changes include, among other things, investments in modernisation of the existing and construction of new infrastructure on the surface. In the results, these are the regions that in particular require monitoring of the present state of old mining terrains in order to assess the existence and character of secondary deformations and their potential effect on the present and planned land development. Observations of present-day movements on old mining terrains can be carried out with a wide array of techniques including for example terrestrial geodetic observations, satellite observations with GNSS, and remote sensing such as satellite based SAR (synthetic aperture radar) sensors or manned and unmanned aerial vehicles that may provide voluminous and frequent sets of data covering the entire area of study at different resolutions. Analysis of the results of such observations requires for proper interpretation also the knowledge on the changes that had occurred in the past, i.e. during the mining period. This information can be fragmentary and limited to selected parts of old mining terrains where mine surveying services had conducted periodic measurements of the surface. However, available sources of height information on old mining terrains in the past for general interpretations may be acquired from old topographic maps (Blachowski and Milczarek, 2014) or results of periodic levelling measurements in precise levelling lines (Blachowski et al., 2009). These sources can provide height data dating back for more than a century and be processed in geographic information systems (GIS) (Blachowski et al., 2014) to provide information on the elevation and changes of the terrain at these times. The drawback being the lack of information between the analysed years.

The main aim of the studies presented in this paper has been to analyse the applicability of using results of repeated national precise levelling measurements and interpolation methods in GIS to determine deformations (vertical movements) on mining terrains in the final stages of underground coal mining and after the end of this activity. Further aims focused on interpreting the character of determined vertical movements on old mining terrains in a period 
of over 40 years (1972-2014). The study has been done on the case of the former Walbrzych Coal Basin area in the city of Walbrzych in SW Poland.

\subsection{CONCISE REVIEW OF RECENT STUDIES OF DEFORMATIONS ON ABANDONED MINING TERRAINS}

The spatial character of mining induced deformations and the amount of quantitative data that need to be processed in mining deformation studies cause that frequently geographical information systems (GIS) and GIS based spatial analysis methods are employed to analyse and assess the character of movements on active and former mining terrains. Recent and noteworthy examples of studies of deformations on old mining terrains augmented with geoinformation systems include old mining sites in South Korea where Oh and Lee $(2010,2011)$ tried to assess ground subsidence spatial hazard near abandoned underground coal mine with the weightsof-evidence model. Oh et al. (2011) have also employed frequency ratio model and sensitivity analysis in GIS to determine causes of ground subsidence for an old mining site. Samsonov et al. (2013) have proposed a method based on processing remote sensing data from synthetic aperture radar (SAR) for studies of ground deformation associated with post-mining activity on the example of a mining site at the French-German border. The proposed method using a time series of SAR images allows precise detection of man-made and natural ground deformation areas providing that enough SAR data is available. Mathey (2013) has applied GIS to study and assess the character of changes occurring on the ground surface and to identify areas of possible hazards due to old underground mining of coal in South Africa. Lee and Park (2013) have analysed ground subsidence hazard using factors that can affect ground subsidence and a decision tree approach in GIS. The effects of post-mining secondary deformation on mining terrains have also been discussed in Preusse et al. (2008), Yu et al. (2006) focused on geohazards associated with rising groundwater due to cessation of pumping from deep mine systems on the example of Durham Coalfield in NE England. In the Netherlands radar interferometry (PS-InSAR) has been used to study recent ground movements on former mining grounds after reported damages in the Zuid-Limburg region almost 40 years after closing of the last mine de Vent and Roest (2013).

In the Walbrzych Coal Basin observations of ground surface subsidence had been carried out at various times and in various parts of the mining terrains during the mining period. The observations were based on periodic measurements of local levelling lines in selected parts of Walbrzych. In the mid-90'ties observations of ground deformations in local sites by mine surveyors have been discontinued. The most comprehensive study was done by Kowalski
(2000) who focussed on the determination of the effects of underground coal mining on ground deformation using empirical modelling based on the Knothe theory (Knothe, 1984). Using this empirical method the theoretical values of subsidence were calculated for the entire period of mining and for the period after World War II. In the first case, the predicted subsidence amounted to $-22 \mathrm{~m}$, and in the second to $-9 \mathrm{~m}$. Recently studies of ground deformations in the mining and post mining times in the Walbrzych Coal Basin have been undertaken in the Geodesy and Geoinformatics Department of the Wroclaw University of Technology (Blachowski et al., 2009; Blachowski and Milczarek, 2014).

\section{MATERIALS AND METHODS}

As stated earlier, the aim of this study has been to determine the extent and magnitude of deformations on mining terrains in the Walbrzych area in the past, i.e. the last two decades of mining and the two decades after the end of mining. The proposed method utilises GIS based interpolation and map algebra functions and the results of periodic national levelling network measurements repeated approx. every 21 years $(1972,1993$ and 2014). The benchmark heights, measured in three consecutive epochs, have been used to calculate vertical movements for a particular benchmark location. Additional aim of the study has been to assess the accuracy and applicability of such data and method for studies of mining terrain deformations in the past.

\subsection{STUDY AREA}

The Walbrzych Coal Basin (WCB), formed part of the former Lower Silesian Coal Basin located in SW Poland and had been the place of hard coal mining for several hundreds of years. This activity ended in the mid-90'ties of $20^{\text {th }}$ Century. After the World War II, the underground operations concentrated in three coal mines named: Victoria, Thorez/Julia and Walbrzych whose mining terrains covered 93.68 $\mathrm{km}^{2}$ (Fig. 1). The geological and mining conditions in the WCB are very specific and difficult in terms of mining. The coal seams associated with three of the four lithostratigraphic Pennsylvanian complexes: the Žaclér, the Biaty Kamien' and the Walbrzych formations, are differentiated in terms of thickness, usually 1 to $2 \mathrm{~m}$, inclination, reaching 30 to 60 degrees and unevenly distributed. Coal formations, located in two synclines (Gorce and Sobięcin) separated by the Chetmiec rhyolite laccolith, are often disturbed by tectonic discontinuities and porphyry intrusions. Altogether, eighty coal seams have been identified there, including 48 in the Žaclér formations and 30 in the Walbrzych formations (Kominowski, 2000). The mineral was extracted with the following mining systems: long-wall and caving (predominately) and long-wall with various forms of fill (pneumatic, dry, dry with material from dead drifts) (Piątek and Piątek, 2002). 


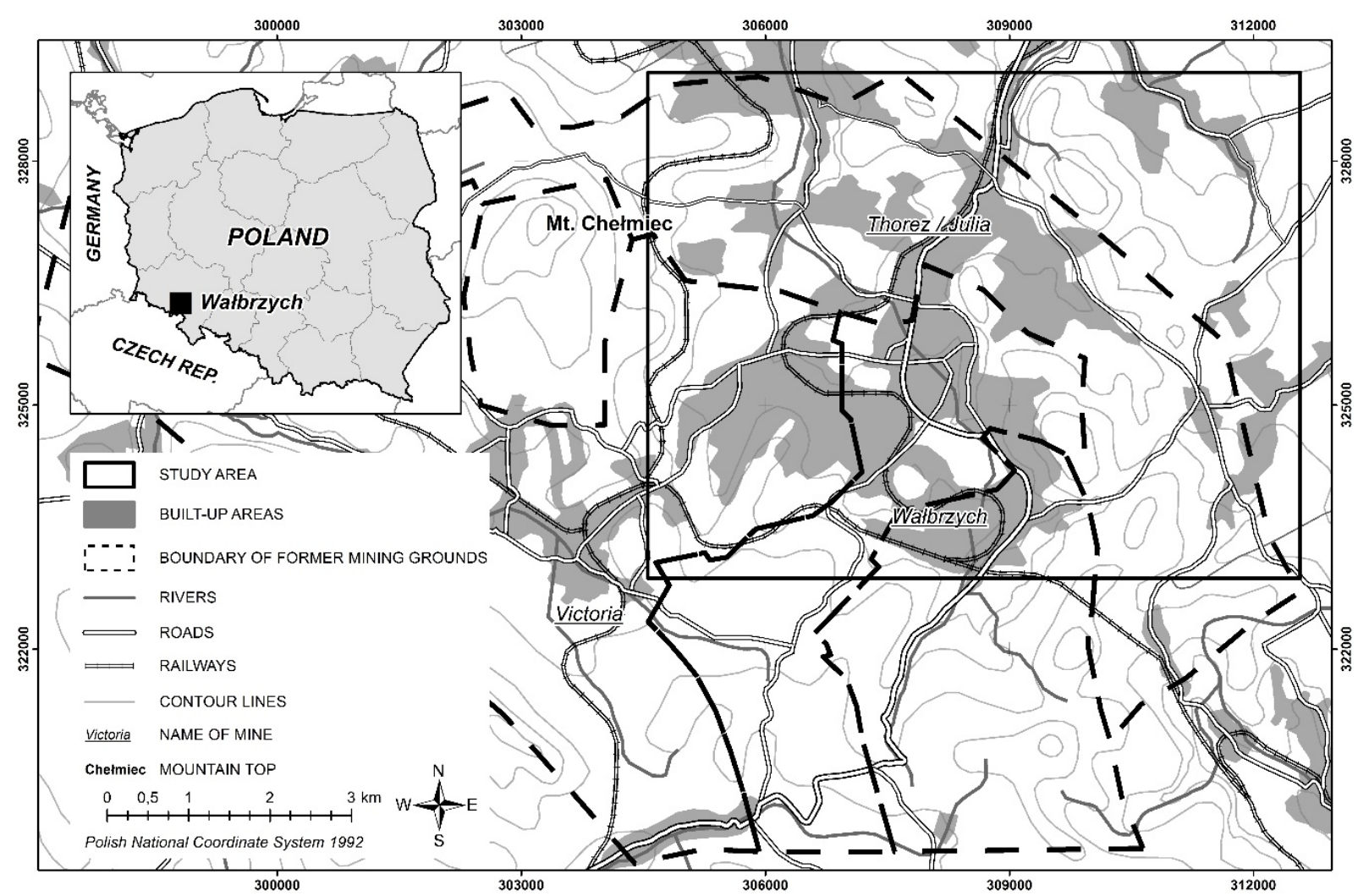

Fig. 1 Location of the Walbrzych Coal Basin and the study area.

The topography of the WCB area is differentiated with wooded hills, the largest being Mt Chelmiec (851 $\mathrm{m}$ a.s.l.), separated by elongated valleys. The valleys are associated with the synclines mentioned earlier. Height differences reach up to $420 \mathrm{~m}$. The long-lasting coal mining caused large and numerous transformations of the original topography. The most significant are: ground subsidence, development of waste dumps and settling ponds, and development of mining and associated infrastructure. The anthropogenic land forms (waste dumps) are often larger (with heights up to $100 \mathrm{~m}$ ) in size than the neighbouring natural forms of the terrain. Examples of man-made waste dumps have been shown in Figure 2. Subsidence basins due to underground mining developed mainly in larger natural depressions (valleys) and are sometimes difficult to detect apart from damages to buildings. Kowalski (2000) holds that the total subsidence during the entire time of mining might have reached $23 \mathrm{~m}$. Wójcik (2008) estimates that 41.8 percent of former mining terrain area has undergone transformation due to the effects of mining activity and notes, natural (Mt. Chelmiec) and anthropogenic (waste dumps, subsidence basins) inversions of topography.

Known examples of secondary deformations on former mining grounds described e.g. in: (Preusse et al., 2008; Oh and Lee, 2010; Samsonov, 2013; de Vent and Roest 2013), as well as the threat of local flooding of subsided areas due to the rise of groundwater to former levels after the cessation of mine water pumping require constant and continuous monitoring of the present day state of mining terrain movements and conditions in Walbrzych.

\subsection{DATA}

The available data comprises of the results of $2^{\text {nd }}$ and $3^{\text {rd }}$ class national levelling measurements realized in 1972, 1993 and 2014 in and around the city of Walbrzych. That means 42 year time span with 3 measurement epochs spaced 21 years apart. The measured levelling network benchmarks are unevenly located over the area of former mining terrains, more densely and more evenly in its $\mathrm{N}$ and $\mathrm{E}$ parts than in the remaining parts. The location of benchmarks is partly forced by local terrain configuration characterized by numerous wooded hills separated by valleys with built-up areas and transport infrastructure. This causes that available dataset is characterized with occurrence of subsets of data forming chains of points separated by unmeasured areas. The borders of the area selected for the purpose of this study have been shown in Figure 1. It extents between $\mathrm{X}=304556 \mathrm{~m}$ to $312575 \mathrm{~m}$ and $\mathrm{Y}=$ $322873 \mathrm{~m}$ to $329090 \mathrm{~m}$ in the 1992 Polish Coordinate System (EPSG code 2180) and covers $49.86 \mathrm{sq} \mathrm{km}$ of the $\mathrm{N}$ and $\mathrm{E}$ parts of the old mining terrains associated with Walbrzych mines, where the number of available benchmark with height measurement in all three epochs is the greatest. The 


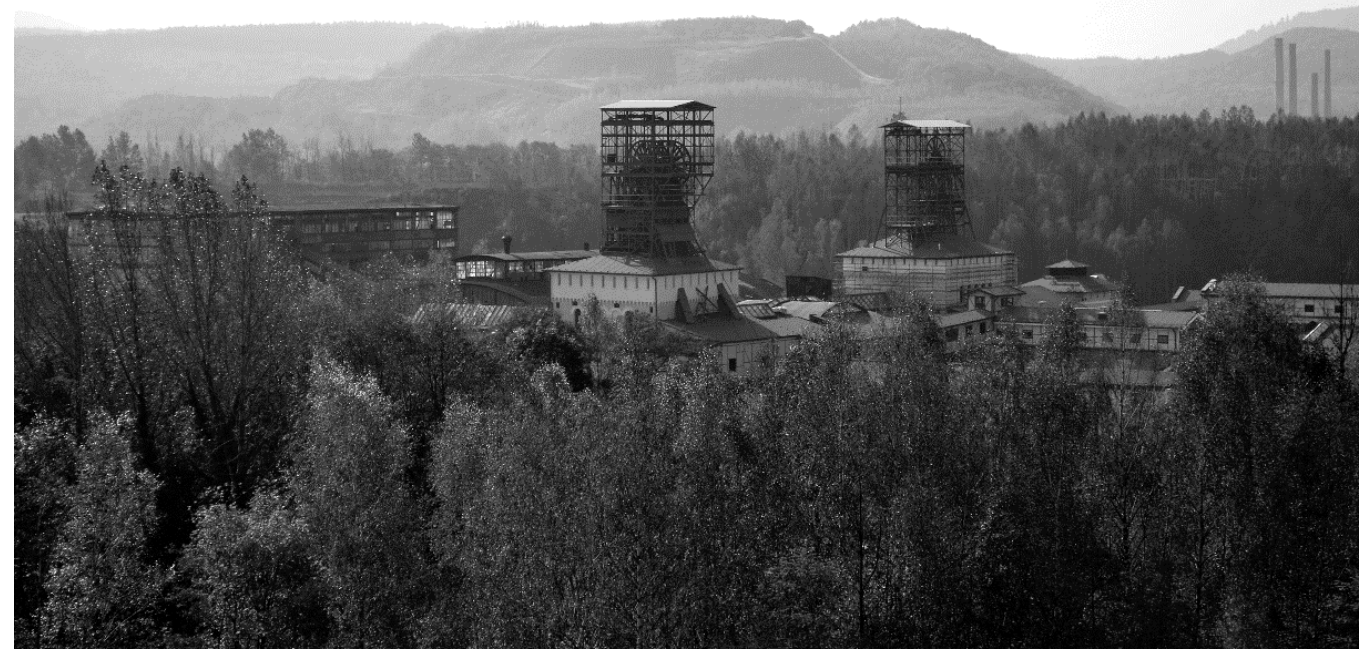

Fig. 2 The present-day remains of the Thorez/Julia mine surface infrastructure and mining waste dumps in the background (photo J. Blachowski, October 2014).

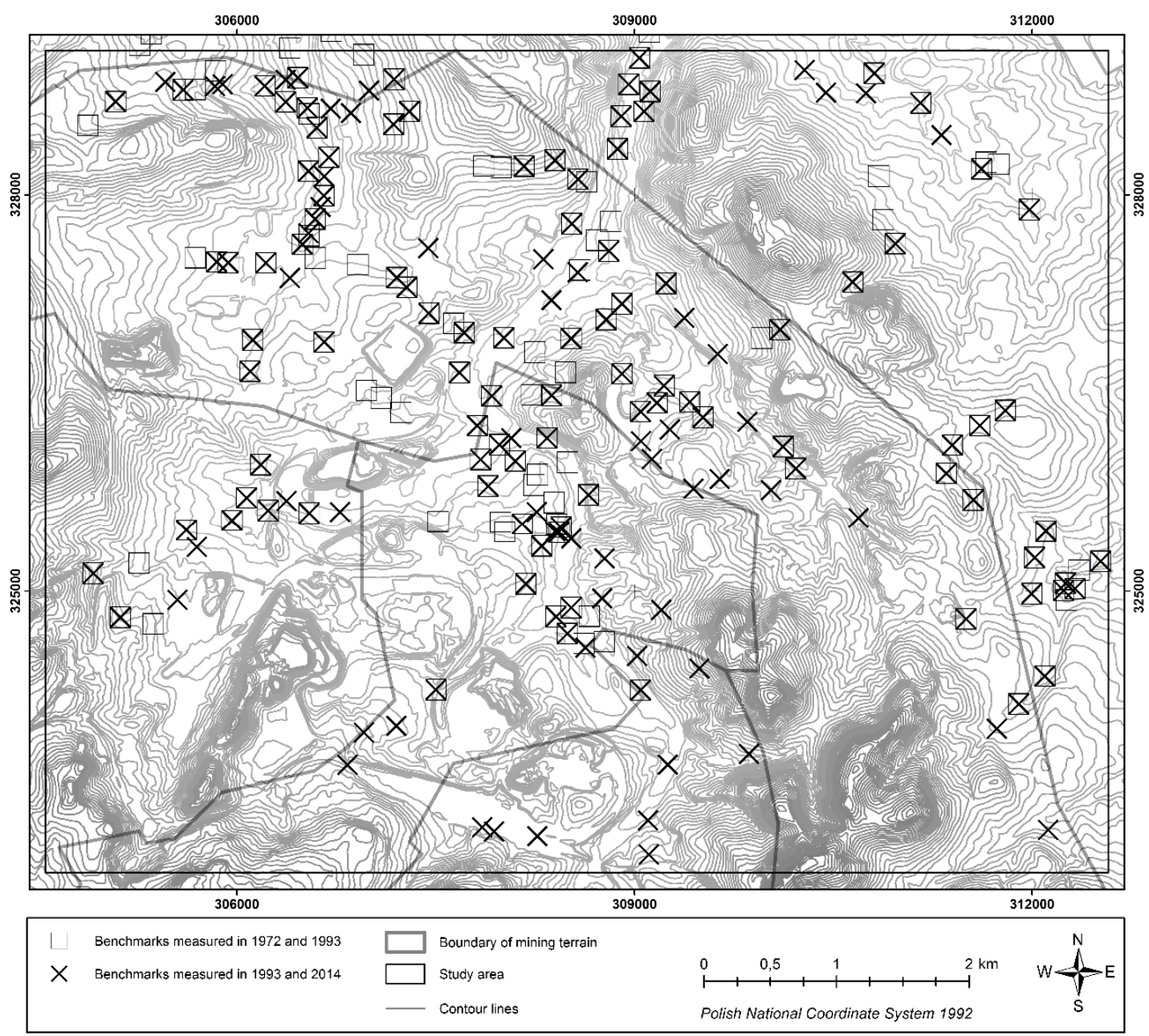

Fig. 3 Locations of the levelling network points against relief. 
Table 1 Results of exploratory data analysis.

\begin{tabular}{lrr}
\hline Statistic & $1972-1993$ & $1993-2014$ \\
\hline Number of mutual points & 143 & 155 \\
Point density & $0.349 \mathrm{~km}^{2}$ & $0.322 \mathrm{~km}^{2}$ \\
Average distance between points & $205.4 \mathrm{~m}$ & $229,0 \mathrm{~m}$ \\
Minimum distance between points & $63.4 \mathrm{~m}$ & $26.8 \mathrm{~m}$ \\
Maximum distance between points & $1008.1 \mathrm{~m}$ & $856.6 \mathrm{~m}$ \\
Maximum negative height change of points & $-0.646 \mathrm{~m}$ & $-0.048 \mathrm{~m}$ \\
Maximum positive height change of points & - & $0.189 \mathrm{~m}$ \\
Number of points with registered subsidence & 143 & $47^{1}$ \\
Number of points with registered elevation & 0 & $106^{1}$ \\
Mean value of height differences & $-0.088 \mathrm{~m}$ & $0.047 \mathrm{~m}$ \\
Standard deviation & 0.116 & 0.054 \\
\hline
\end{tabular}

${ }^{1}$ - two points without measured vertical movement between the observation epochs

selected area is also representative in terms of the extent of underground mine workings, topography, and land development $(35.7 \%$ of land taken by builtup area) areas for the entire region of old mining terrains. The location of benchmarks within the study area is presented in Figure 3.

The number of points measured between 1972 and 1993 is 143, whereas between 1993 and 2014, 155 points have been measured. Summary of statistics from exploratory data analysis has been given in Table 1.

\subsection{METHODOLOGY}

The data described in part 3.2 has been used to interpolate vertical movement of the ground surface using six interpolation methods available in the Geostatistical Analyst and Spatial Analyst extensions of the ESRI ArcGIS v10.2 software. To calculate vertical movements between the 1972-1993 and 19932014 periods, the following methods have been used: inverse distance weighted (IDW) (Shepard, 1968), radial basis function (RBF) (Hardy, 1990), local polynomial (LPI) (ESRI, 2015), kriging (KRI) (Olea, 1999), spline (SPL) (Franke, 1982) and natural neighbour (NN) (Sibson, 1981). A related approach has been adopted by Kowalczyk et al. (2010) to map vertical movements on a nationwide scale for the area of Poland.

The IDW, RBF, LPI, SPL and NN methods belong to a group of deterministic interpolation methods using mathematical functions and values measured in sampled points, whereas kriging is a stochastic interpolation method taking into account stochastic (random) models to account for randomness in the data (Heywood, 2006). The IDW, RBF, SPL and NN methods are exact i.e. at each input data location, the surface will have exactly the same value as the input data value, whereas LPI and KRI methods are approximate, i.e. at each input data location, the surface may not have the same value as the input data. The KRI method requires a model of spatial autocorrelation to generate predicted values, the IDW method implicitly assumes spatial autocorrelation in the data where higher power values imply shorter ranges of spatial autocorrelation. The other methods do not require a model of spatial autocorrelation (ESRI, 2015).

The input data have been processed for optimised parameters of each interpolation method, chosen to minimize the root mean square error $\left(m_{R M S}\right)$ determined with cross-validation technique (Hofierka et al., 2007). The $m_{R M S}$ is calculated as follows (1):

$m_{R M S}=\sqrt{\frac{\sum_{i=1}^{n}\left(z_{i}-z_{i}^{\prime}\right)^{2}}{n}}$

where:

$z_{i}-$ vertical movement measured at a point $i$,

$z^{\prime}{ }_{i}$ - vertical movement estimated at point $i$,

$n$ - number of points.

In the first step, the vertical movements of individual benchmarks have been calculated subtracting the results of the 1993 levelling measurement from the 1972 one and subtracting the results of the 2014 levelling measurement from the 1993 one. In the next step, the calculated vertical movements in the two analysed periods have been used to produce maps of vertical movements using the above-mentioned interpolation methods. Next, the accuracies of particular interpolations have been analysed. Based on the results of accuracy analysis (Table 2) and the characteristics of particular interpolation method, the spline one has been selected as the most appropriate to map vertical movements of the terrain in the first (1972-1993) and in the second (1993-2014) of the analysed periods. The rms value for the spline generated map of vertical movements in first period is the lowest. The same is true for the second period. The rms values for the IDW and kriging methods are also low for the first period, however the IDW method does not estimate values below or above the minimum and the maximum values of the input data, which is important in analysing mining induced deformations and the 
Table 2 Results of accuracy analysis for 1972-1993 and 1993-2014 interpolations.

\begin{tabular}{lcc}
\hline \multicolumn{1}{c}{$\begin{array}{c}\text { Interpolation } \\
\text { method }\end{array}$} & $\begin{array}{c}1972-1993 \\
\text { RMS values [m] }\end{array}$ & $\begin{array}{c}1993-2014 \\
\text { RMS values [m] }\end{array}$ \\
\hline Inverse Distance Weighted & 0.0049 & 0.0024 \\
Radial Basis Function & 0.0092 & 0.0023 \\
Local Polynomial & 0.0403 & 0.0261 \\
Spline & 0.0048 & 0.0019 \\
Natural Neighbour & 0.0071 & 0.0031 \\
Kriging & 0.0049 & 0.0079 \\
\hline
\end{tabular}

surface generated in the result of kriging interpolation is less uniform then the other interpolation methods.

The map of vertical movements for the entire period (1972-2014) has been obtained in the result of map algebra operation (addition) on the two raster maps representing vertical movements in the 19721993 and the 1992-2014 periods. The results have been presented and commented in the next section (3). This procedure has allowed to use more data (points with calculated vertical movements) for analysis, as the number of mutual points between 1972 and 1993, and between 1993 and 2014 differ and are greater than the number of mutual points between 1972 and 2014 .

\section{RESULTS AND DISCUSSION}

Figure 4 shows map of vertical movements between 1972 and 1993 and coal parcels, marked in red, mined since 1970 until the end of mining in mid90'ties. This period corresponds to the final two decades of coal mining in the Walbrzych area. During this time the entire mining terrain area experienced subsidence. The regions of greatest subsidence, marked with dark blue occurred in the western part of the study area. Two main subsidence regions are located there, larger arch-shaped one (max. subsidence $-0.730 \mathrm{~m}$ ) and a smaller one north of the first one. Another region of subsidence can been seen in the eastern part of mining terrains marked with lighter blue ( $\max$. subsidence $-0.254 \mathrm{~m}$ ). The area between these two regions, marked with light blue in the central part of the map, experienced almost no subsidence during this time. The maximum value of subsidence calculated from benchmark height differences between 1972 and 1993 is $-0.646 \mathrm{~m}$. The maximum value of subsidence interpolated with spline interpolation is $-0.730 \mathrm{~m}$. These values give max. negative vertical movement of $-0.031 \mathrm{~m} /$ year for benchmark and max. negative vertical movement of $-0.034 \mathrm{~m} /$ year for the estimated surface.

Figure 5 shows map of vertical movements between 1993 and 2014. This 21 year period corresponds to the time after end of underground coal mining in Walbrzych. Unlike in the first analysed period, the second one is characterised by differentiated vertical movements of mining terrain. The analysed area experienced both subsidence and elevation. The regions that have risen are located in the central, north-western, northern and north-eastern parts of the former mining terrains and marked with warm colours (red, orange and yellow). The maximum value of positive vertical movement calculated from benchmark height differences is $+0.189 \mathrm{~m}$. The elevated regions are separated by two smaller regions of subsidence marked with cold colours (blue and green). Subsidence can also be observed in the southwestern and south-eastern parts of the former mining terrains. The maximum value of subsidence calculated from benchmark height differences between 1993 and 2014 is $-0.048 \mathrm{~m}$ whereas the max. positive vertical movement is $+0.189 \mathrm{~m}$. These values give max. negative vertical movement of $-0.002 \mathrm{~m} /$ year and max. positive vertical movement of $+0.009 \mathrm{~m} / \mathrm{year}$ respectively. The regions that experienced upward movement in the 1993-2014 period correspond to regions that experienced the greatest subsidence in the previous period (Fig. 4). The subsidence observed in the northern and eastern parts of the study area occurs beyond the borders of former mining grounds and may also be attributed to factors other than mining for example regional geodynamics. This phenomenon could be a subject of a different study and further investigated on a larger scale and area.

Figure 6 presents map of total vertical movements observed in the 42 year period against the background of built-up areas and has been obtained in the result of adding the two raster maps presented in Figure 4 and Figure 5. The mining terrain area is characterised by differentiated vertical movements of mining terrain. In the regions of greatest subsidence observed on map (Fig. 4) the rebound of the terrain after the end of mining (the second period) has not compensated completely for the earlier subsidence and the total vertical movement in these parts (dark blue) amounts to max. $-0.620 \mathrm{~m}$. However, in the central and eastern parts, the magnitude of upward movement in the latter period has exceeded the magnitude of downward movement in the preceding period and the total vertical movement in these parts (light green) amounts to $+0.100 \mathrm{~m}$. These results suggest that the vertical movements associated with reaction of the ground after the end of mining in the analysed part of mining terrains have not yet ceased and require constant and periodic observations also due to possible other, probably endogenous, factors. 
We must note that the presented results, due to the number of available measurement points, irregular configuration and distances between the levelling network points (Fig. 3) may have caused probable omission of very local variations in vertical movements of the terrain. In addition, the interval of measurements (21 years) may cause that dynamics of vertical movements and possible change of direction of these movements have been unnoticed. Nevertheless, these results constitute an approximate but real picture of vertical movements in the analysed area, and are especially important in a situation when other sources of information are unavailable.

\section{CONCLUSIONS}

The authors, aiming to study mining terrain deformations in the final stages of underground coal mining and in the two decades after its end have encountered the problem of obtaining quantitative data on vertical movements. The Walbrzych Coal Basin (study area) had been periodically measured by mine surveyors in local levelling lines and these measurements had stopped after the mines have been closed. In addition, results of these observations provide information on vertical movements on a very local scale, that is limited to particular buildings or groups of buildings on the surface. In the end, the available source of information for the study consisted of the results of three national precise levelling campaigns that covered most of the study area.

Taking into account the characteristics of the six interpolation methods used and the results of accuracy analysis, the results of the spline interpolation have been used to analyse interpret the vertical movements in the considered time span.

In the first analysed period (1972-1993) that corresponds to the last two decades of mining, the results of interpolation of vertical movements registered in the measured benchmarks indicate subsidence on the entire study area. The calculated vertical movement of mining terrains $-0.034 \mathrm{~m} /$ year is an averaged value for the 21 year period that might have been different if shorter periods of time could have been considered.

In the second analysed period (1993-2014) that corresponds to the time after the end of mining, the results of interpolation of vertical movements registered in the measured benchmarks show both subsidence and elevation. The areas of greatest elevation in the second period correspond to the areas of greatest subsidence in the earlier period. The magnitude of vertical movements, $-0.002 \mathrm{~m} /$ year (subsidence) and $+0.009 \mathrm{~m} /$ year (elevation) is several times smaller than in the first period but shows present-day secondary movements on old mining terrains. The difference between max. registered subsidence and elevation values amounts to $0.237 \mathrm{~m}$. The differentiated and more complicated character of vertical movements in the second period with both subsidence and elevation areas should be observed further in more detail.

The presented results show that even after many years after the end of underground mining the mining terrains remain active.

\section{ACKNOWLEDGMENTS}

This work has been financed from the Polish National Science Centre Project „Development of a numerical method of mining ground deformation modelling in complex geological and mining conditions" UMO-2012/07/B/ST10/04297 executed at the Faculty of Geoengineering, Mining and Geology of the Wroclaw University of Technology (Poland).

\section{REFERENCES}

Blachowski, J. and Milczarek, W.: 2014, Analysis of surface changes in the Wałbrzych hard coal mining grounds (SW Poland) between 1886 and 2009. Geological Quarterly, 58, No. 2, 353-367. DOI: 10.7306/gq.1162

Blachowski, J., Chrzanowski, A. and Szostak-Chrzanowski, A.: 2014, Application of GIS methods in assessing effects of mining activity on surface infrastructure. Archives of Mining Sciences, 59, No. 2, 307-321. DOI: $10.2478 / \mathrm{amsc}-2014-0022$

Blachowski, J., Cacoń, S. and Milczarek, W.: 2009, Analysis of post-mining ground deformations caused by underground coal extraction in complicated geological conditions. Acta Geodyn. Geomater., 6., No 3.(155), 351-357.

ESRI, 2015. ArcGIS Desktop Help, @ http://help.arcgis.com/en/arcgisdesktop/10.0/help/index.ht $\mathrm{ml}$, accessed 2015-02-06.

Franke, R.: 1982, Smooth interpolation of scattered data by local thin plate splines. Computer and Mathematics with Applications, 8, No. 4, 273-281. DOI: $10.1016 / 0898-1221(82) 90009-8$

Hardy, R.: 1990, Theory and applications of the multiquadric-biharmonic method, interpolation, 20 years of Discovery, 1968 1988. Computers Mathematical Applications, 19, No. 8/9, 163-208. DOI: 10.1016/0898-1221(90)90272-L

Heywood, I., Cornelius, S. and Carver, S.: 2006, An Introduction to Geographic Information System, 3rd Edition, Pearson, Prentice Hall, Essex, England.

Hofierka, J., Cebecauer, T. and Š́ri, M.: 2007, Optimisation of interpolation parameters using cross-validation. In: Peckham, R. J. and Jordan, G. (Eds.), Digital Terrain Modelling, Lecture Notes in Geoinformation and Cartography, Springer, 67-82. DOI: 10.1007/978-3-540-36731-4_3

Knothe, S.: 1984, Forecasting the influence of mining (in Polish). Śląsk Publishing, House Katowice.

Kominowski, K.: 2000, Geology and hydrogeology (in Polish). In: Kowalski, A. (Ed.) Mining and surface protection. Experiences from the Walbrzych mines. Central Mining Institute, Katowice, 33-48.

Kowalczyk, K., Rapiński, J. and Mróz, M.: 2010, Analysis of vertical movements modelling through various interpolation techniques. Acta Geodyn. Geomater., 7, No. 4(160), 399-409.

Kowalski, A. (Ed.): 2000, Mining and surface protection. Experiences from the Walbrzych mines (in Polish). Central Mining Institute, Katowice. 
Lee, S. and Park, I.: 2013, Application of decision tree model for the ground subsidence hazard mapping near abandoned underground coal mines. Journal of Environmental Management, 127, 166-176. DOI: $10.1016 /$ j.jenvman.2013.04.010

Mathey, M.: 2013, Addressing the challenges involved with abandoned underground coal mines in South Africa. XV International ISM Congress 2013 Proceedings, $113-123$.

Oh, H.J. and Lee, S.: 2010, Assessment of ground subsidence using GIS and the weights-of-evidence model. Engineering Geology, 115, No. 1-2, 36-48. DOI: 10.1016/j.enggeo.2010.06.015

Oh, H.J. and Lee, S.: 2011, Integration of ground subsidence hazard maps of abandoned coal mines in Samcheok, Korea. International Journal of Coal Geology, 86, 5872. DOI: $10.1016 /$ j.coal.2010.11.009

Oh, H.J., Ahn, S.Ch., Choi, J.K. and Lee, S.: 2011, Sensitivity analysis for the GIS-based mapping of the ground subsidence hazard near abandoned underground coal mines. Environmental Earth Sciences, 64, 347-358. DOI: $10.1007 / \mathrm{s} 12665-010-0855-1$

Olea, R.A.: 1999, Geostatistics for Engineers and Earth Scientists. Kluwer Academic Publishers, Boston, USA.

Piątek, E. and Piątek, Z:: 2002, Summary of the history of the Lower Silesia coal mining 1434-2000. @ http://www.boehm-chronik.com/bergbau/gorn14342000.pdf, accessed 2012-08-24.

Preusse, A., Kateloe, H.J. and Sroka, A.: 2008, Future demands on mining subsidence engineering in theory and practice. Gospodarka Surowcami Mineralnymi Mineral Resource Management, Meeri, 24, No. 3/1, $15-26$.
Samsonov, S., d'Oreye, N. and Smets, B.: 2013, Ground deformation associated with post-mining activity at the French-German border revealed by novel InSAR time series method. International Journal of Applied Earth Observation and Geoinformation, 23, 142-154. DOI: 10.1016/j.jag.2012.12.008

Shepar, D.: 1968, A two-dimensional interpolation function for irregularly-spaced data. Proc. 23rd National Conference ACM, 517-524.

Sibson, R.: 1981, A Brief Description of Natural Neighbor Interpolation. In: Interpolating Multivariate Data. New York: John Wiley \& Sons, 21-36.

de Vent, I. and Roest, H.: 2013, Lagging mining damage in the Netherlands? Recent signs of soil movement in the Zuid-Limburg coal district. XV International ISM Congress 2013 Proceedings, 113-123.

Wójcik, J.: 2008, Surface change due to mining in the Walbrzych area (in Polish with English summary). Landform Analysis, 9, 339-342.

$\mathrm{Yu}$, M.H., Jefferson, I. and Culshaw, M.: 2006, Geohazards caused by rising groundwater in the Durham Coalfield, U.K. Proceedings of the $10^{\text {th }}$ IAEG International Congress, Nottingham, United Kingdom, 6-10 September 2006.

\section{ATTACHEMENTS}

Maps of vertical movements on mining terrains (1993-2014) obtained with six interpolation techniques 

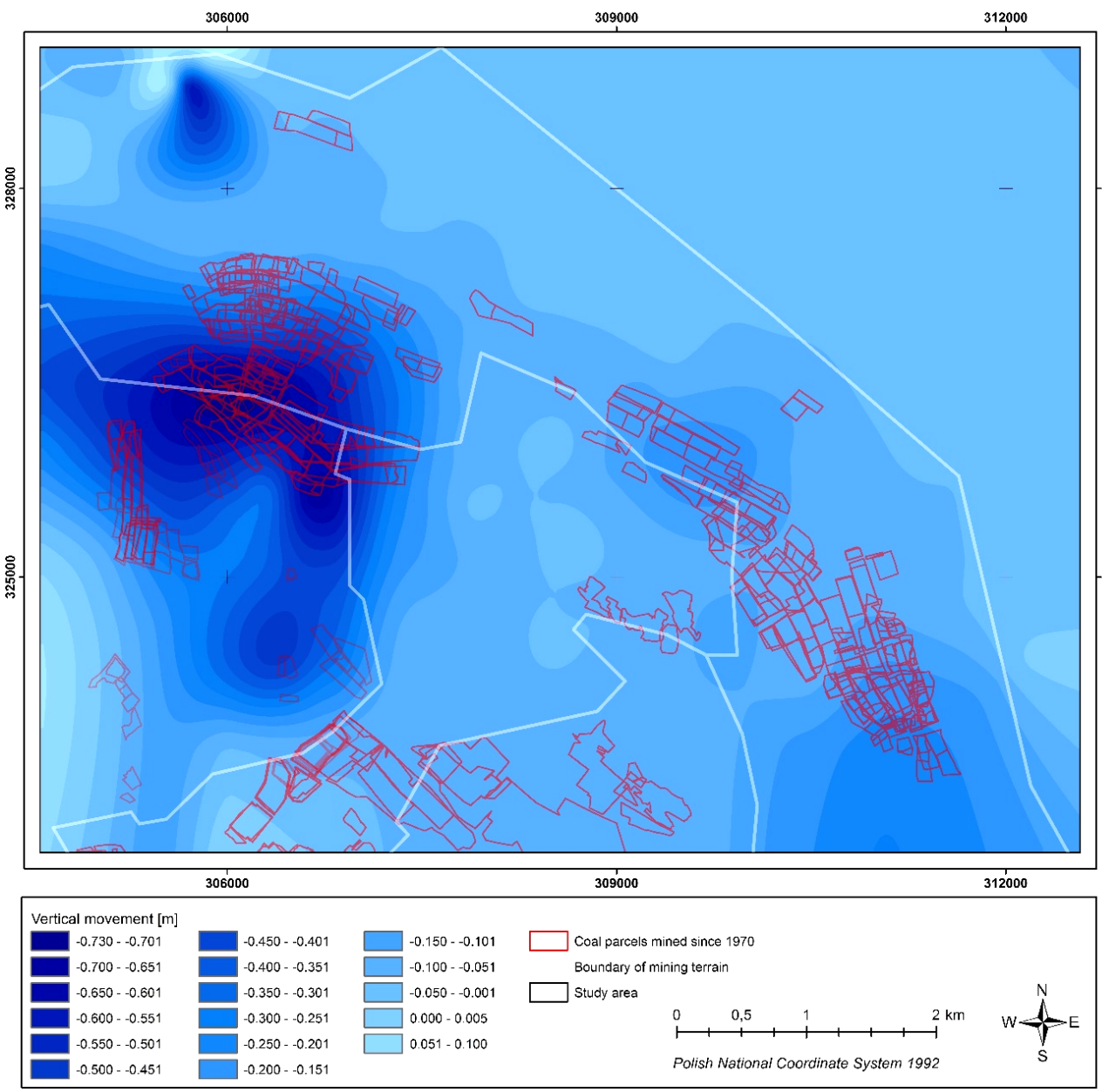

Fig. 4 Vertical movements, 1973-1992 period, interpolated with spline interpolation method against the background of coal parcels mined since 1970.

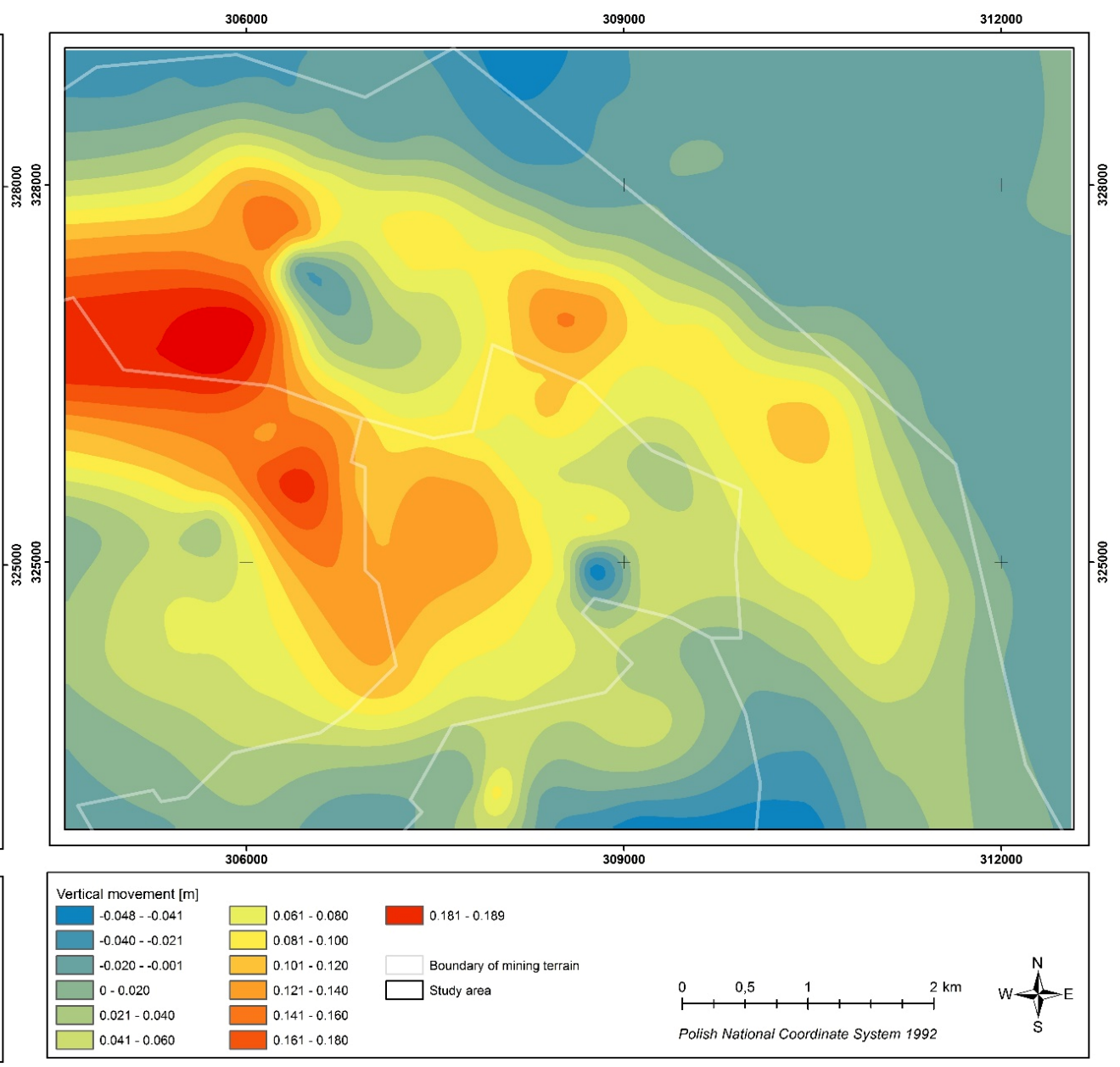

Fig. 5 Vertical movements, 1992-2014 period, interpolated with spline interpolation method. 


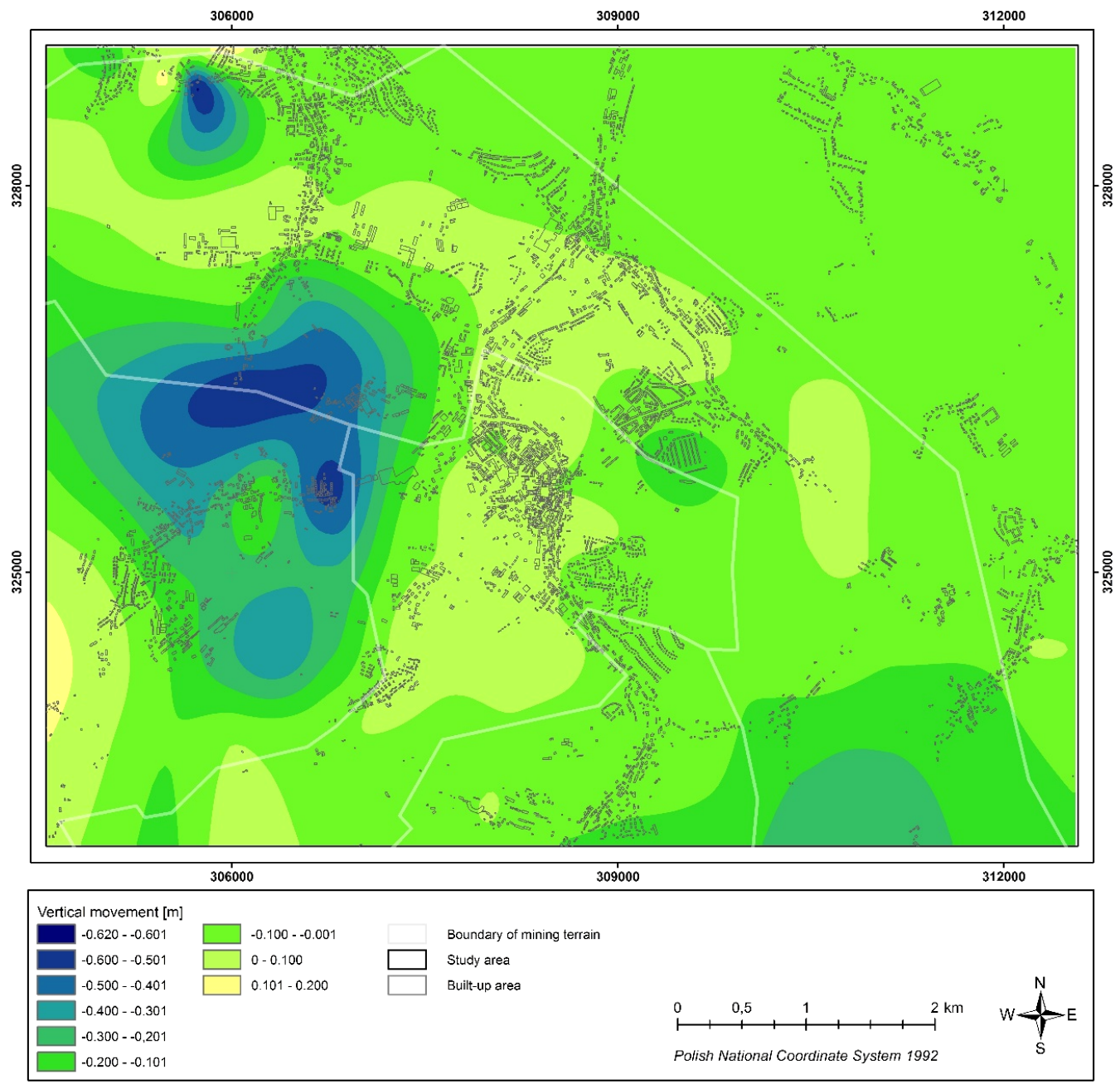

Fig. 6 Vertical movements calculated for the 1973-2014 period and built-up areas.
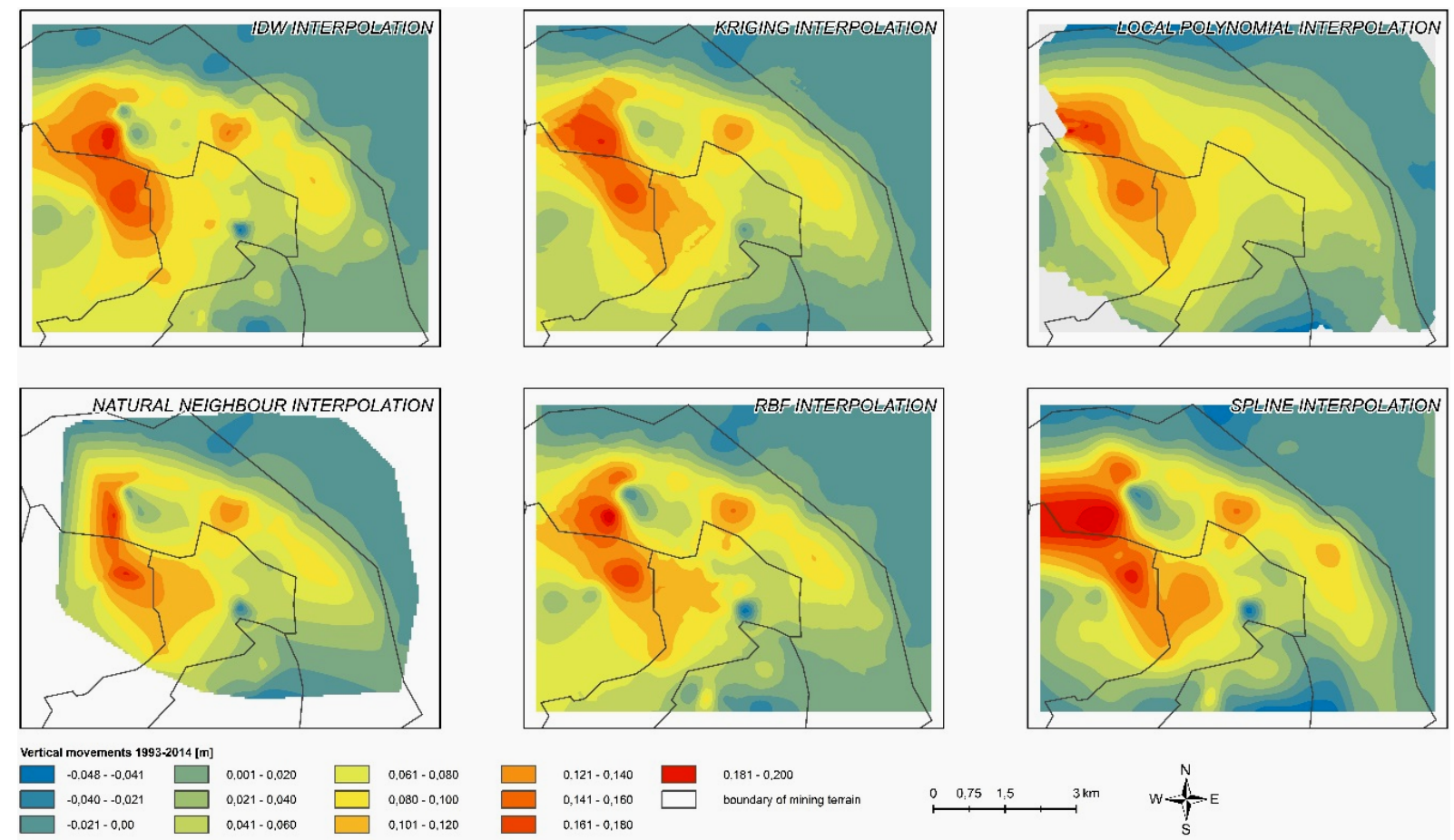

ATTACHEMENTS Maps of vertical movements on mining terrains (1993-2014) obtained with six interpolation techniques. 